DOE/ET/53088---8

DE92 040014

\title{
ESTABLISHMENT OF AN INSTITUTE FOR FUSION STUDIES
}

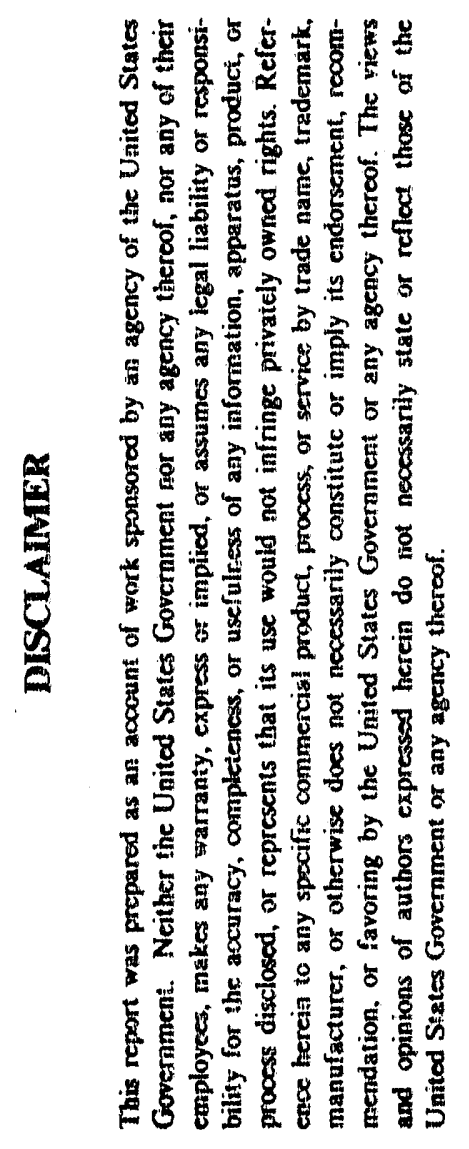

\author{
Technical Progress Report
}

November 1, 1991 - October 31, 1992

Richard D. Hazeltine, Director

Institute for Fusion Studies

The University of "Texas at Austin

Austin, Texas 78712

July 1992

PREPARED FOR THE U.S. DEPARTMENT OF ENERGY UNDER GRANT NUMBER DE.FG05-80ET53088

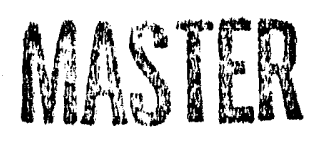

1, 


\section{TABLE OF CONTENTS}

INTRODUCTION 3

$\begin{array}{ll}\text { TECHNICAL PROGRESS AND RFSULTS } & 4\end{array}$

$\begin{array}{ll}\text { IFS PUBLICATIONS (FY 92) } & 10\end{array}$

$\begin{array}{ll}\text { VISITORS (1991-1992) } & 18\end{array}$

LIST OF IFS REPORTS (1991-1992) 22

ABSTRACTS OF IFS REPORTS (1991-1992) 30 


\title{
Technical Progress Report \\ for the Grant DE-FG05-80ET53088 \\ "Establishment of an Institute for Fusion Studies" \\ for the period November 1, 1991 to October 31, 1992
}

\author{
Richard D. Hazeltine, Director \\ Institute for Fusion Studies, The University of Texas at Austin \\ Austin, Texas $\mathbf{7 8 7 1 2}$
}

\section{Introduction}

The Institute for Fusion Stusies is a national center for theoretical fusion plasma physics research. Its purposes are: (1) to conduct research on theoretical questions concerning the achievement of controlled fusion energy by means of magnetic confinement--including both funcamental problems of long-range significance, as well as shorter-term issues; (2) to serve as a center for information exchange, nationally and internationally, by hosting exchange visits, conferences, and workshops; (3) and to train students and postdoctoral research personnel for the fusion energy program and plasma physics research areas.

The theoretical research results that are obtained by the Institute contribute mainly to the progress of national and international efforts in nuclear fusion research, whose goal is the development of fusion power as a basic energy source. In addition to its primary focus on fusion physics, the Institute is also involved with research in related fields, such as advanced computing techniques, nonlinear dynamics, plasma astrophysics, and accelerator physics. The work of IFS scientists continued to receive national and international recognition. Numerous invited papers were given during the past year at workshops, conferences, and scientific meetings. Last year IFS scientists published 95 scientific articles in technical journals and monographs.

The Institute actively sponsors collaborative research programs with laboratories and universities throughout the U.S. and the world. Last year, the IFS hosted 41 short-term visitors and 2.7 long-term (i.e., one month or more) visitors. In particular, on behalf of the Department of Energy, the IFS is the principal site in the United States for the exchange activities of the U.S.Japan Joint Institute for Fusion Theory. Each year this program normally includes two workshops in each country, six exchange scientist visits, and several joint computational projects on the USJapanese international computer data link.

In addition to its research activities, the IFS has a significant educational function. Last year 17 graduate students worked on fusion and plasma physics thesis-degree projects under the supervision of senior IFS scientists, who also teach courses in the Physics Department. Three of these students gradıated with Ph.D. degrees last year. Also, as part of its educational role, the Institute has a postdoctoral training program, which involved 9 postdoctoral fellows last year. 


\section{Technical Progress and Results}

During FY 1992, a number of noteworthy scientific advances were achieved, relative to both long-range fundamental problems as well as near-term issues. Examples of these achievements include studies of ion temperature gradient driven turbulent transport, alpha-particle driven toroidal Alfvén eigenmode stability, simulations for the Numerical Tokamak Project, and mathematical ptysics. Many of these projects were done in collaboratinn with scientists from other institutions. Important research discoveries (concerning which space limitations allow only brief and selective description) were attained in the following areas:

\section{Tokamak Dynamics}

The nonlinear evolution of the $\mathrm{m}=1$ mode was examined in high-temperature plasmas where the mode is either in the semi-collisional or collisionless regime. In either regime, the mode exhibits nonlinearly enhanced growth rates that far exceed their linear values, thus making their nonlinear evolution collisionless. This accelerated growth may explain the fast sawtooth crashes observed in large tokamaks.

Investigation was continued of a novel method proposed for stabilizing or reducing the growth rate of $m=1$ tearing $n$,odes by means of resonance detuning caused by jittering the rational surface. A kinetic treatment of this method revealed several new leatures, including the need for external forcing of electrons to prevent runaway.

A kinetic theory of $\mathrm{ff}$ current drive and helicity injection showed that a wave helicity flux perpendicular to the magnetic field does not influence the parallel motion of electrons to leading order and therefore will not drive a significant current. This result is relevant to the quest for efticient current drive methods in a tokamak.

The behavior of tearing instabilities in the presence of equilibrium flow and X-point reconriection was analyzed in slab geometry. A nonlinear MHD code exhibits the existence of oscillating islands. With current-free X-points, there is either relaxation back to equilibrium or instability to the formation of current sheets.

Reduced thuid models, based on the large aspect ratio approximation, were studied with the use of Hamiltonian perturbation theory and action principles.

The field lines of tokamak poloidal divertors were studied with the use of integrable areapreserving maps. These results are useful for understanding the effect of electromagnetic limiter fields on the divertor, e.g., in the TEXT tokamak.

\section{Edge physics}

The effects of charge-exchange processes, which are believed to play a key role in determining appropriate boundary conditions on plasma transport, were calculated. In particular, an analytical kinetic theory of neutral density profiles at long charge-exchange mean free path, as well as a generalized theory of ion rotation damping, are being developed. 
Also, the question was examined of how the ion density varies near the separatrix in a divertor tokamak, where large values of the safety factor imply that all ions are into the collisional regime, regardless of pitch angle.

Kinetic theory was developed for the edge region in tokamaks where the electrostatic potential varies radially on the scale length of the poloidal gyroradius; this theory allows the effect: of orbit squeezing and enhanced trapping on ion transport to be taken into account. Monte-Carlo simulations of ion orbits in the edge electric field are underway.

Also, the description of a toroidally rotating tokamak plasma was generalized to allow for rapid poloidal rotation, which is apparently associated with edge effects.

The conducting end-wall electron temperature gradient instability was applied to the scrapeoff layer of a tokamak, yielding results consistent with the scrape-off width observed in experiments.

Edge turbulence was studied from the point of view of mode identification and driving source. It was shown that the dissipative drift wave can be destabilized by impurity condensation associated with radiative cooling. Also, the potential drive due to ionization is strongly dependent on the manner in which the equilibrium is achieved. Both of these conclusions contradict earlier results that had been proposed elsewhere. In related work, turbulence suppression by arbitrary shear flow was found to occur essentially at moderate values for the shear flow.

\section{Turbulence and Plasma Transport}

Analytic studies of ion ternperature gradient driven transport were continued. The effect of anisotropy in the ion temperature and that of temperature gradient were examined for the toroidal $\eta_{i}$ mode. A fully kinetic and nonlocal description of this mode was obtained from a numerical solution of the gyrokinetic equation in ballooning space. In the electromagnetic regime, a new mixing length formula was proposed to explain the experimentally observed radially increasing profile and the parameter scaling for the ion thermal conductivity $\chi_{\mathrm{i}}(\mathrm{r})$. Electromagnetic effects on the toroidal electron temperature gradient driven modes were studied and found to be destabilizing, unlike in slab geometry. Also, the kinetic $\eta_{i}$ mode was studied in the presence of ion flow shear: poloidal flow shear was found to be stabilizing, whereas toroidal flow shear is destabilizing. which is in qualitative agreement with experimental observations on edge turbulence. The effects of impurities were also examined.

A large project on analyzing drift wave and $\eta_{i}$ mode stability and transport in the TFTR tokamak density modification experiments was completed in collaboration with Princeton experimentalists. This analysis showed that the $\eta_{i}$ mode can explain the experimental power balance in transport in these high- $\mathrm{T}_{\mathrm{i}}$, high- $\nabla \mathrm{T}_{\mathrm{i}}$ experiments, earlier thought to disagree with theory. 
The ion temperature gradient mode was investigated numerically with the use of the TPC particle code, for the case of a flat density profile, in order to simulate the behavior of an $\mathrm{H}$-mode tokamak plasma.

The neoclassical viscosity effect on conventional resistive tearing and resistive ballooning modes was studied by the derivation and numerical solution of the linearized flux-surface-averaged resistive MHD boundary layer equations, including the neoclassical viscosity, the diamagnetic drift, and the compressibility terms in general toroidal geometry.

A major new direction in the solutions for drift wave vortices in a shear magnetic field was discovered. Both theory and simulations show the validity of the concept of drift wave vortices in such a sheared field.

A new model was developed for the nonlinear interactions of multiple-helicity versus single-helicity drift waves. The theory indicates that single-helicity modes play a dominant role in establishing the radial profile of the anomalous transport. This model introduces the density of states for the localized drift waves and shows that it leads to strongly radially increasing profiles for the thermal diffusivities.

The transport caused by the emission and absorption of electron plasma waves was studied by considering the wakefield of a superthermal test electron in a magnetized plasma. An enhancement of the transport of momentum and energy due to such waves was found that exceeded the level that had been previously predicted elsewhere.

Tokamak transport in a turbulent electromagnetic field was analyzed with neoclassical effects taken into account. The transport coefficients so obtained are weakly sensitive to the spectrum and amplitude of the fluctuations and may explain anomalous ion transport in a tokamak.

Particle trajectories in a toroidal system with strong poloidal and toroidal asymmetry was investigated. This study is the basis for analyzing transport in a tokamak under ECRH heating or with vertically asymmetric field ripple (which can occur for a vertically displaced plasma column).

\section{Computational Plasma Physics}

The IFS becane a partner in a multi-institutional consortium for a joint project to develop a "numerical tokamak," which would simulate turbulent transport in the core plasma. This grandchallenge project is part of a program of research related to the current High Performance Computing and Communications Initiative of the federal govemment.

In particular, the IFS continued to be active in the development of a large-scale numerical tokamak model with the TPC code, a toroidal-geometry, general-coordinate-metric, particlesimulation code. TPC simulations of heat transport and particle diffusion induced by $\eta_{\mathrm{i}}$ modes were found to give perhaps the first-ever numerical results for the ion thermal diffusivity that have the same value and radial profile as in experimental observations. Correlations with observed tluctuation spectra indicate that toroidal mode coupling may explain the observed heat transport. The TPC code is being augmented with gyrokinetic and low-noise ("delta-f") algorithms, as well 
as a Darwin-type model for representing self-consistent magnetic fields. Also, a portable scientific plot package used by the TPC code is being released in beta test form to users at other institutions. In a collaboration with the Microelectronics and Computer Technology Corporation, the TPC code is being used to test new MCC software for distributed computing.

A parallel effort to develop a particle simulation code for studies of transport and stability in full toroidal geometry was initiated. So far, an electrostatic version with a full-dynamics pusher for electrons and ions that uses cotventional algorithms, a full-dynamics pusher with a low-noise ("delta-f") algorithm, and a model with drift-kinetic electrons that uses either a conventional or a delta-f algorithm has been constructed and tested. The progress of this effort (as well as the TPC program) has been greatly facilitated by the extensive utilization of high-performance work stations that the Institute purchased last year.

A three-dimensional gyrokinetic spectral code was also employed to simulate the turbulence driven by the ion temperature gradient instability in a toroidal annulus. It was found that thermal diffusivities in toroidal geometry are much larger than previous results in slab geometry and are approaching experimentally observed values.

\section{Alpha Particle Physics}

A topic of great concern to proposed ignition experiments like ITER, as well as to D-T operation in the TFTR and JET tokamaks, is the behavior of the toroidal Alfven eigenmode. Previous work at the IFS had predicted that these waves can be strongly excited by alpha particles, which was confirmed by recent experiments at Princeton and General Atomics that used neutral beam-injected fast ions to simulate the alpha particles. Current IFS studies have studied several aspects of the TAE modes. A high-rnode-number theory was developed to calculate selfconsistently their damping due to resonance with the shear Alfvén continuum. The inclusion of electron parallel dynamics was shown to be able to influence the TAE damping rate, through coupling to the kinetic Alfvén wave under conditions that depend on the gap size, the shear, the magnitude of the parallel conductivity, and the mode numbers. The finite size of the alpha particle orbit excursion from a flux surface, which can cause a decrease in the interaction strength when the orbit size is comparable to or larger than the mode width, was taken into account in estimating the destabilization of 'TAE's in an ignition plasma. Mapping methods were developed to describe the nonlinear dynamics of the interaction of alpha particles and Alfvern waves. Stochasticity thresholds were estimated, and the quasilinear problem was addressed. In particular, scenarios for alpha particle evolution were defined, ranging from benign pulsations, to phase-space explosions in which the alpha particles rapidly diffuse radially to the outer region of the plasma. Also, in collaboration with General Atomics, an Alfvén wave numerical code is being extended to toroidal geometry, with the goal of studying antenna-driven TAE and GAE modes, as well as their utility for current drive. 
The strong electric field that is usually observed near the edge of an $\mathrm{H}$-mode tokamak plasma was found to modify the dispersion curves of the toroidal shear Alfvén wave significantly: when the radial electric field shear in the ExB drift overcomes magnetic shear, the Alfvén "gap" mode disappears, and two resonances arise that lead to a Kelvin-Helmholtz instability.

A new mechanism, viz., the two-energy-stream cyclotron instability, by which fast ions (e.g., fusion-product protons or alpha particles) can excite electrostatic Bernstein waves was investigated. This mechanism yields a possible explanation for the ion cyclotron emission observed in experiments on the JET tokamak with D-D and D-T fueling.

\section{Nonlinear Dynamics and Mathematical Physics}

The free energy principle for nonlinear instability of neutral negative-energy modes was obtained, and an expression for the free energy in terms of the electric field and for the case of incompressible fluids was derived. Arnold diffusion was investigated as a mechanism for nonlinear instability to arbitrarily small perturbations, which is completely overlooked by conventional linear stability analysis when negative energy modes are present. Contour dynamics, a model that contains much of the physics of vortex dynamics, was employed to find the existence of negative energy modes.

The symplectic structure of the Vlasov equation was investigated. With the use of the Hamiltonian structure, a phase space description that is sirnilar to that for quantum mechanics was obtained for the first time for Maxwell's equations.

Explicit solutions, both analytical and numerical, were found for the nonlinear VlasovPoisson system that describe the time evolution of an inhomogeneous collisionless plasma. The solution is given in terms of a double perturbation series, with the infinite sum of interaction terms performable exactly due to the property of dynamical factorization.

\section{Advanced Ideas}

The stability of "compact" (i.e., with finite axial length) field-reversed configurations for confining a plasma whose ions consist mostly of an energetic beam component was analyzed; the potential for ignition in this novel concept of a self-collider is being studied. Ancther interesting advanced concept that had been proposed for plasma confinement, a "magnetless" system, was further explored.

A theory for describing high-Reynolds-number MHD fluids in terms of magnetic filaments was developed.

The limits of validity for the well-known ballooning representation were systematically analyzed for toroidal drift waves in a non-ideal plasma.

A theoretical description was given for the amplification mechanism of the ion-ripple laser, which is an advanced scheme for generating coherent high-power radiation. 
A new idea for using a mirror machine as a neutron source was proposed. To obtain high $\mathrm{Q}$ in a mirror neutron source, the electron temperature needs to be about or greater than $2 \mathrm{keV}$. Typically, however, open-ended mirrors have an electron temperature that is an order of magnitude less than this. In this new proposal, an elliptically elongated toroidal link contains the electrons in a low beta region, while minimum- $B$ fields are used in the high-beta region. In this way, it may be possible to achieve large neutron flux with high efficiency.

Some work was done on plasma theory applied to high-energy particle accelerators. A theory for noise in the rf system of the SSC collider rings was applied to the growth of longitudinal emittance due to intrinsic sources of noise and its contribution to luminosity loss, and to the extraction of low-intensity beams from the SSC for fixed target physics. A proposal for an experimental test of these ic eas on the Tevatron was recently approved.

Fluid mechanical analogies of nonlinear drift wave dynamics were explored. A "standard non-twist" map was derived that exhibits separation reconnection and an unusual path to global chaos. This map is relevant to finite-degree-of-freedom Hamiltonian system techniques, which describe transport of dye in rotating tank experiments.

\section{Conclusion}

Institute work continued to receive national and international recognition. At the 1991 APS Plasma Physics Meeting. T. Tajima presented an invited paper, "On Zero Frequency Magnetic Fluctuations in Plasmas" and A. Beklemishev presented an invited paper, "Anomalous Ion Thermal Diffusion from $\eta_{i}$ Modes". At the 1992 Annual Controlled Fusion Theory Sherwood Conference, invited papers on "Map Model for Nonlinear Alpha Particle Interaction with Toroidal Alfvén Eigenmodes", by H. Ye and "Nonlinear Drift Wave Structures in a Sheared Magnetic Field", by X. Su were presented. Numerous invited papers given during the past year at other workshops, conferences, and international meetings could also be cited.

Although the Institute for Fusion Studies has no formal programmatic or experimental support responsibility, it does contribute to the national and international fusion scientific effort in a variety of ways. Close collaborative relationships have been developed with university and national laboratory fusion groups, both in the US and abroad. Advanced theoretical and computational techniques are being developed and disseminated; a broad spectrum of cnnfinement devices are being investigated; and, in addition to primarily fusion plasma physics $w c k \mathrm{k}$, contacts are being maintained with the fields of fluid dynamics, computational mathematics, statistical mechanics. accelerator physics, and space physics. The diversity of the research performed at the Institute is reflected in the attached list of recent IFS publications. 


\section{IFS Publications During FY 92}

I. Aranson, B. Meerson, and T. Tajima, "Excitation of solitons by an external resonant wave with a slowly varying phase velocity," Phys. Rev. A 45, 7500 (1992).

K. Avinash, "Dynamo effect and current drive due to magnetic fluctuations in sheared magnetic field," Phys. Fluids B 3, 2150 (1991).

A.Y. Aydemir, "Linear studies of $m=1$ modes in high-temperature plasmas with a four-field model," Phys. Fluids B 3, 3025 (1991).

A. D. Beklemishev and W. Horton, "Transport profiles induced by radially localized modes in a tokamak," Phys. Fluids B 4, 200 (1992).

A.D. Beklemishev and W. Horton, "Anomalous ion thermal diffusion from $\eta_{i}$ modes," Phys. Fluids B 4, 2176 (1992).

H.L. Berk, J.W. Van Dam, Z. Guo, and D.M. Lindberg, "Continuum damping of low-n toroidicity-induced shear Alfvén eigenmodes," Phys. Fluids B 4, 1806 (1992).

H. L. Berk, B. N. Breizman, and H. Ye, "Finite orbit energetic particle linear response to toroidal Alfvén eigenmodes," Phys. Lett. A 162, 475 (1992).

H.L. Berk, D.D. Ryutov, G.V. Stupakov, Yu. A. Tsidulko, "Instability effects caused by conducting end walls in a plasma on open field lines," in Plasma Physics and Controlled Nuclear Fusion Research 1990 (IAEA, Vienna, 1991), vol. 2, p. 289.

I. Bialynicki-Birula and P. J. Morrison, "Quantum mechanics as a generalization of Nambu dynamics to the Weyl-Wigner formalism," Phys. Lett. A 158, 453 (1991).

R.V. Bravenec, K.W. Gentle, B. Richards, D.W. Ross, D.C. Sing, A.J. Wootton, D.L. Brower, N.C. Luhmann, Jr., W.A. Peebles, C.X. Yu, T.P. Crowley, J.W. Heard, R.L. Hickok, P.M. Schoch, X.Z. Yang, "Core turbulence and transport studies on the Texas Experimental Tokamak," Phys. Fluids B 4, 2127 (1992).

B. Breizman, T. Tajima, D.L. Fisher, and P.Z. Chebotaev, "Excitation of nonlinear wake field in a plasma for particle acceleration," published in Research Trends in Nonlinear and Relativistic Effects in Plasmas, ed. V. Stefan, (AIP, New York, 1991).

A. Brizard, T. K. Fowler, D. Hua, and P. J. Morrison, "Extremal bounds on drift wave growth rates and transport," Comments on Plasma Physics 14, 263 (1991).

K.R. Chen and J. Dawson, "Ion Ripple Laser,", Phys. Rev. Letts. 68, 29 (1992).

X. L. Chen and P. J. Morrison, "Nonlinear interactions of tearing modes in the presence of shear flow," Phys. Fluids B 4, 845 (1992). 
C.Z. Cheng, R.B. White, G.Y. Fu, L. Chen, D.J. Sigmar, C.T. Hsu, A. Beklemishev, H.L. Berk, B. Breizman, S.C. Guo, Z. Guo, D. Lindberg, J.W. Van Dam, "Alpha particle effects on global MHD modes, and alpha particle transport in ignited Tokamaks," in Plasma Physics and Controlled Nuclear Fusion Research 1990 (IAEA, Vienna, 1991), vol. 2, p. 209.

J.W. Connor, R.J. Hastie and J.B. Taylor, "Resonant magnetohydrodynarnic modes with toroidal coupling. Part I: Tearing modes," Phys. Fluids B 3, 1532 (1991).

J.W. Connor, R.J. Hastie and J.B. Taylor, "Resonant magnetohydrodynamic modes with toroidal coupling. Part II: Ballooning-twisting modes," Phys. Fluids B 3, 1539 (1991).

D. del-Castillo-Negrete and P. J. Morrison, "Hamiltonian chaos and transport in quasi-geostrophic flows," in Research Trends in Physics, Chaotic Dynamics, and Transport in Fluids and Plasmas, edited by V. Stephan et al. (American Institute of Physics, New York, 1992).

J. Q. Dong, W. Horton, and J. Y. Kim, "Toroidal kinetic $\eta_{i}$-mode study in high temperature plasmas," Phys. Fluids B 4, 1867 (1992).

S. Eliezer, T. Tajima, and R. M. Kulsrud, "A muon catalyzed fusion reactor and direct conversion of the catalysed energy," in Plasma Physics and Controlled Nuclear Fusion Research 1990 (IAEA, Vienna, 1991), vol. 3, p. 617.

K. W. Gentle and R. D. Hazeltine, "A practical limitation on transport by ripple-trapped ions," Phys. Fluids B 3, 3198 (1991).

K. W. Gentle, B. Richards, M. E. Austin, R. V. Bravenec, D. L. Brower, R. F. Gandy, W. L. Li, P. E. Phillips, D. W. Ross, W. L. Rowan, P. M. Schoch, P. M. Valanju, and A. J. Wootton, "Equilibrium and perturbed fluxes and turbulence levels in a tokamak: implications for models," Phys. Rev. Lett. 68, 2444 (1992).

S. Hamaguchi and W. Horton, "Modeiling of drift wave turbulence with a finite ion temperature gradient," Plasma Phys. and Contr. Fusion 34, 203 (1992).

S. Hamaguchi and W. Horton, "Effects of shear flows on ion-temperature-gradient-driven turbulent transport," Phys. Fluids B 4, 319 (1992).

H. Hanami and T. Tajima, "Numerical study of compressible solar magnetoconvection with an ope: transitional boundary," Ap. J. 377, 694 (1991).

A.B. Hassam, T.M. Antonsen, Jr., A.M. Dimits, J.F. Drake, P.N. Guzdar, Y.T. Lau, C.S. Liu, K.C. Shaing, P.J. Christenson, W.A. Houlberg, R.D. Hazeltine, "Spontaneous poloidal spin-up of Tokamaks and the transition to H-Mode," in Plasma Physics and Controlled Nuclear Fusion Research 1990 (IAEA, Vienna, 1991), vol. 2, p. 311. 
T. Hayashi, A. Takei, N. Ohyabu, T. Sato, M. Wakatani, H. Sugama, M. Yagi, K. Watanabe, B.G. Hong, W. Horton, "Equilibrium beta limit and anomalous transport studies of helical systems," in Plasma Physics and Controlled Nuclear Fusion Research 1990) (IAEA, Vienna, 1991), vol. 2, p. 143.

R. D. Hazeltine, M. D. Calvin, P. M. Valanju, and E. R. Solano, "Analytical calculation of neutral transport and its effect on ions," Nucl. Fusion 32, 3 (1992).

R.L. Hickok, P.M. Schoch, T.P. Crowley, J.W. Heard, K.W. Gentle, D.W. Ross, A.J. Wootton, B. Richards, W.L. Rowan, D.L. Brower, W.L. Li, N.C. Luhmann, Jr., W.A. Peebles, C.Y. Yu, "Turbulent fluctuations and transport in TEXT," in Plasma Physics and Controlled Nuclear Fusion Research 1990 (IAEA, Vienna, 1991), vol. 1, p. 229.

K.A. Holcomb and T. Tajima, "A mechanism for gamma-ray bursts by Alfvén-wave acceleration in a non-uniform atmosphere," Ap. J. 378, 682 (1991).

B.-G. Hong, W. Horton, S. Hamaguchi, M. Wakatani, M. Yagi, and H. Sugama, "Transition from resistive-g to $\eta_{\mathrm{i}}$-driven turbulence in stellarator systems," Phys. Fluids B 3, 1638 (1991).

W. Horton, D. Lindberg, J. Y. Kim, J. Q. Dong, G. W. Hammett, S. D. Scott, M. C. Zarnstorff, and S. Hamaguchi, "Ion-temperature-gradient-driven transport in a density modification experiment on the Tokamak. Fusion Test Reactor," Phys. Fluids B 4, 953 (1992).

W. Horton, C. Liu, B. Burns, T. Tajima, "Collisionless plasma transport across loop magnetic fields," Phys. Fluids B 3, 2192 (1991).

W. Horton, C. Liu, J. Hernandez, and T. Tajima, "Stochastic mixing of protons from chaotic orbits in the nightside geomagnetosphere," Geophys. Res. Lett. 18, 1575 (1991).

W. Horton and T. Tajima, "Transport from chaotic orbits in the geomagnetic tail," Geophys. Res. Lett. 18, 1583 (1991).

W. Horton and T. Tajima, "Collisionless Conductivity and Stochastic Heating of the Plasma Sheet in the Geomagnetic Tail," J. Geophys. Res. 96, 15811 (1991).

W. Horton, J. Hernandez, J.Y. Kim, and T. Tajima, "Orbital Stability, Transport, and Convective Heating in the Current Sheet Plasma," in Physics of Space Plasmas (1991), SPI Conference Proceedings and Reprint Series, Number 11, eds. T. Chang, G.B. Crew, and J.R. Jasperse, (Scientific Publishers, Cambridge, MA, 1992) pp. 225-262.

A. Ishida, L.C. Steinhauer, and H.L. Berk, "Variational form for a viscous plasma," Phys. Fluids B 3, 1552 (1991).

M. B. Isichenko and W. Horton, "Scaling laws of stochastic ExB plasma transport," Comments Plasma Phys. Contr. Fusion 14, 249 (1991). 
M. B. Isichenko, "Effective plasma heat conductivity in 'braided' magnetic field--1. Quasi-linear limit," Plasma Physics and Controlled Fusion 33, 795 (1991).

M. B. Isichenko, "Effective plasma heat conductivity in 'braided' magnetic field-.Il. Percolation limit," Plasma Physics and Controlled Fusion 33, 809 (1991).

M.B. Isichenko and J. Kaida, "Statistical topography. I. Fractal dimension of coastlines and number-area rule for islands," J. Nonlinear Sci. 1, 255 (1991).

M.B. Isichenko and J. Kalda, "Statistical topography. II. Two-dimensional transport of a poszive scalar." J. Nonlinear Sci. 1, 375 (1991).

M.B. Isichenko and J. Kalda, "Arymz'ous resistance of randomly inhomogeneous Hall media," Zh. Eksp. Teor. Fiz, 99. 224 (1991); [Sov. Phys. JETP 72(1), 126 (1991)].

M.B. Isichenko and J. Kalda, "Geometrical effects in magnetoresistance," J. Muscow Phys. Soc. 2, 1 (1992).

M.B. Litchenko, "Percolation, statistical topogrąhy, and transport in random media," to appear in Rev. Mod. Phys. 64(4), (1992).

K. Jungwirth and B.N. Breizman, "Nonlinear dynamics of one-dimensional supersonic, Langmuir waves," Phys. Fluids B 3, 2174 (1991).

M. Kaisig, T. Tajima, and R.V.E. Lovelace, "Magnetic 'nterchange Instability of Accretion Disks," Ap. J. 386, 83 (1992).

M. Kaisig, T. Tajima, and M. Ryutova, "Absorption of Magnetoacoustic Waves in the Solar Atmosphere with Random Irhomogeneities of Density and Magnetic Fields," Elare Physics in Solar Aclivity Maximum 22, eds. Y. Uchida, R.C. Canfield, T. Watanabe, and E. Hiei, (SpringerVerlag, Berlin, 1994) p. 287.

T. Kamimura, E. Montalvo, D.C. Barnes, J.N. Leboeuf, and T. Tajima, "Implicit Particle Simulation of Electromagnetic Plasma Phenomiena," J. Comp. Phys. 100. 77 (1992).

W. Kernbichler, M. Heindler, H. Momota, Y. Tomita, A. Ishida, S. Ohi, M. Ohnishi, K. Sato, G.H. Miley, H.L. Berk, W. Dove, "D. ${ }^{3} \mathrm{He}$ in field reversed configurations-RUBY: An International Reactor Study," in Plasma Physics and Controlled Nuclear Fusion Research 1990 (IAEA, Vienna, 1991), vol. 3, p. 555.

J. Y. Kim and W. Horton, "Electromagnetic effect on the toroidal electron temperature gradient mode," Phys. Fluids B 3, 3194 (1901).

J. Y. Kim, W. Horton, D. I. Choi, S. Migliuolo, and B. Coppi, "Temperature anisotropy effect on the toroidal ion temperature gradient mode," Phys. Fluids B 4, 15.2 (1992). 
T. Kurki-Suonio and T. Tajima, "Transport model of optical beams in a plasma," J. Comp. Phys. 94, $186(1991)$.

M. Konc and W. Horton, "'Point vortex description of drift wave vortices: dynamics and transport," Phys. Fluids B 3, 3255 (1991).

M. Kotschenreuther, H.L. Berk, R. Denton, S. Hamaguchi, W. Horton, C.-B. Kim, M. Lebrun, P. Lyster, S. Mahajan, W.H. Miner, P.J. Morrison, D.W. Ross, R.D. Sydora, T. Tajima, J.B. Taylor, P.M. Valanju, H.V. Wong, S.Y. Xiao, Y.-Z. Zhang, "Novel computational techniques to predict transport in confinereant devices, and applications to ion temperatire gradient driven turbulence," in Plasma Physics and Controlled Nuclear Fusion Research 1990 (IAEA. Vienna. 1991), vol. 2. p. 361 .

B. Meerson and T. Tajima, "A mesoscopic linear accelerator driven by super-intense subpicosecond laser pulses," Optics Com. 86, 283 (1991).

R. R. Mett and J, B. Taylor, "Steady-state dynamo and current drive in a nonuniform bounded plasma," Phys. Fluids B 4, 73 (1992).

R. R. Mett, "Kinetic theory of rf current drive and helicity injection," Phys. Fluids B 4, 225 (1992).

K. Mima, K. Yoshikawa, O. Mnrimiya, H. Takase, H. Takabe, Y. Kitagawa, T. Tajima, K. Yasuji, and S. Nakai, "Direct energy conversion in a D.3He inertial confinement fusion reactor," accepted by Fusion Tech. (1991).

B. Newberger and H.-J. Shih, "Low intensity beam extraction at the SSC," in Nonlinear Dynamics and Particle Acceleration, edited by Y. H. Ichikawa and T. Tajima, AIP Cont. Proc. \#230 (American Institute of Physics, New York, 1991), p. 251.

B. Narwerger, "Laser plasma interactions and particle acceleration," in The Physics of Particle Accelerators, edited by M. Month and M. Dienes, AIP Conf. Proc. \#249 (American Institute of Physics, New York, 1992), p. 1075.

S. Nozawa, K. Shibata, R. Matsumoto, A.C. Sterling, T. Tajima, Y. Uchida, A. Fertari, and R. Rosner, "Emergence of magnetic flux from the convection zone into the solar atmosphere. I. lineas and nonlinear adiabatic evolution of the Convective-Parker instability," Ap. J. Suppl. 78, 267 (1992).

M. G. Prahovic, R. D. Hazeltine, and P. J. Morrison, "Exact solutions for a system of nonlinear plasma fluid equations," Phys. Fluids B 4, 831 (1992). 
D.J. Rej, M. Tuszewski, D.C. Barnes, A.D. Bailey, G.A. Barnes, M.H. Baron, R.E.Chrien, J.W. Cobb, A. Ishida, R.E. Siemon, J.L. Staudenmeier, S. Sugimoto, D.P. Taggart, T. Takahashi, R.B. Webster, B.L. Wright, "Tilt stability and compression heating studies of fieldreversed configurations," in Plasma Physics and Controlled Nuclear Fusion Research 1990 (IAEA, Vienna, 1991), vol. 2, p. 647.

B. Richards, M. E. Austin, R. V. Bravenec, D. L. Erower, K. W. Gentle, R. L. Hickok, N. C. Luhmann, A. Ouroua, W. A. Peebles, P. E. Phillips, D. W. Ross, W. L. Rowan, P. M. Schoch, P. M. Valanju, J. C. Wiley, A. J. Wootton, X. Z. Yang. and C. X. Yu, "Tests of plasma transport models via perturbation techniques," Nucl. Fusion 32, 567 (1992).

M. N. Rosenbluth, H. L. Berk, J. W. Van Dam, and D. M. Lindberg, "Continuum damping of high-mode-number toroidal Alfvén waves," Phys. Rev. Lett. 68, 596 (1992).

M.N. Rosenbluth, H.L. Berk, J.W. Van Dam, and D.M. Lindberg, "Mode structure and continuum damping of high-n toroidal Alfvén eigenmodes," Phys. Fluids B 4, 2189 (1992).

D. W. Ross, "On standard forms for ransport equations and quasilinear fluxes," Plasma Phys. and Contr. Fusion 34, 137 (1992).

D. W. Ross, M. L. Sloan, A. J. Wootton, P. M. Schoch, J. W. Heard, T. P. Crowley, R. L. Hickok, and V. Simcic, "Effect of beam attenuation modulation on fluctuation measurements by heavy ion beam probe," Rev. Sci. Instriments 63, 2232 (1992).

D. W. Ross, P. M. Schoch, J. W. Heard, T. P. Crowley, and R. L. Hickok, "Dispersion relations of density fluctuations observed by the heavy on beam probe in TEXT," Nucl. Fusion 31, 1355 (1991).

D. W. Ross, R. V. Bravenec, C. P. Ritz, M. L. Sloan, J. R. Thompson, A. J. Wootton, P. M. Schoch, J. W. Heard, T. P. Crowley, R. L. Hickok, V. Simcic, D. L. Brower, W. A. Peebles, and N. C. Luhmann, Jr., "Comparison of drift wave models with fluctuation data from the interior of the TEXT tokamak." Phys. Fluids B 3, 2251 (1991).

M. Roy and T. Tajima, "The effect of hot inhomogeneous plasma on geomagnetic micropulsations," J. Atmos. Terr. Phys. 54, 209 (1992).

M. Ryutova, M. Kaisig, and T. Tajima, "Propagation of magnetoacoustic waves in the solar atmosphere with random inhomogeneities of density and magnetic fields," Ap. J. 380, 268 (1991).

K. C. Shaing, R. D. Hazeline, and H. Sanuki, "Shock formation in a poloidally rotating tokamak plasma," Phys. Fluids B 4, 04 (1992).

K. Shibata, S. Nozawa, "K. Matsumoto, T. Tajima, and A.C. Sterling, "Atmospheric heating in emerging tlux regions," to be published in Prec. Heidalberg Conference on Mechanisms of Chromospheric and Coronal Heating, ed. P. Ulmschneider, (Springer-Verlag, Berlin, 1991). 
X. Su, W. Horton, and P. J. Morrison, "Drift wave vortices in nonuniform plasmas with sheared magnetic fields," Phys. Fluids B 4, 1238 (1992).

T. Tajima, S. Cable, K. Shibata, and R.M. Kulsrud, "On the origin of cosmological magnetic fields," Ap. J. 390, 309 (1992); also in Primordial Nucleosynthesis and Evolution of Early Universe, eds. K. Sato and J. Audouze, (Kluwer, Dordrecht, 1991) p. 423.

T. Tajima and J. Koga, "Beam-bearn interaction simulations of the SSC," in Proc. Nonlinear Dynamics and Particle Acceleration, eds. Y. Ichikawa and T. Tajima, (American Institute of Physics, New York, 1991) p. 236.

T. Tajima, S. Eliezer, and R.M. Kulsrud, "Direct conversion of muon catalyzed fusion energy," Muon Cat. Fusion 7, 47 (1992).

T. Tajima, S. Cable, and R.M. Kulsrud, "On zero frequency magnetic fluctuations in plasmas," Phys. Fluids B 4. 2338 (1992).

A.A. Ware, R.D. Hazeltine, M. Calvin, P.M. Valanju, E. Solano, "Effect of low energy ions and neutrals on Tokamak transport," in Plasma Physics and Controlled Nuclear Fusion Research 1990 (IAEA, Vienna, 1991), vol. 2, p. 351.

H. Vernon Wong, H.L. Berk, R.V. Lovelace, and N. Rostoker, "Stability of annular equilibrium of energetic large orbit ion beam," Phys. Fluids B 3, 2973 (1991).

H. Xiao, R. Carrera, and R. D. Hazeltine, "Self-consistent radial sheath in ignited plasmas," Nuclear Fusion 31, 2162 (1991).

X. Q. Xu and M.N. Rosenbluth, "Unified theory of ballooning instabilities and temperature gradient-driven trapped ion modes," Phys. Fluids B 3, 1807 (1991).

J. G. Yang, Y. H. Oh, D. I. Choi, J. Y. Kim, and W. Horton, "Neoclassical viscosity effects on resistive magnetohydrodynamic modes in toroidal geometry," Phys. Fluids B 4, 659 (1992).

X.Z. Yang, B.Z. Zhang, A.J. Wootwn, P.M. Schoch, B. Richards, D. Baldwin, D.L. Brower, G.G. Castle, R.D. Hazeltine, J.W. Heard, R.L. Hickok, W.L. Li, H. Lin, S.C. McCool, V.J. Simcic, Ch. P. Ritz, and C.X. Yu, "The space potential in the tokamak TEXT," Phys. Fluids B 3, 3448 (1991).

H. Ye and P. J. Morrison, "Action principles for the Vlasov equation," Phys. Fluids B 4, 771 (1992).

H. Ye, P. J. Morrison, and J. D. Crawford, "Poisson bracket for the Vlasov equation on a symplectic leaf," Phys. Lett. A 156, 96 (1991).

H. Ye and Allan N. Kaufman, "Self-consisterit theory for ion gyroresonance," Phys. Fluids B 4, 1735 (1992). 
P. Yushmanov, "Neoclassical diffusion in a turbulent plasma," Comments Plasma Phys. Contr. Fusion 14, 313 (1992).

M.C. Zarnstorff, C.W. Barnes, P.C. Efthimion, G.W. Hammett, W. Horton, R.A. Hulse, D.K. Mansfield, E.S. Marmar, K.M. McGuire, G. Rewoldt, B.C. Stratton, E.J. Synakowski, W.M. Tang, J.L. Terry, X.Q. Xu, M.G. Bell, M. Bitter, N.L. Bretz, R. Budney, C.E. Bush, P.H. Diamond, R.J. Fonck, E.D. Fredrickson, H.P. Furth, R.J. Goldston, B. Grek, R.J. Hawryluk, K.W. Hill, H. Hsuan, D.W. Johnson, D.C. McCune, D.M. Meade, D. Mueller, D.K. Owens, H.K. Park, A.T. Ramsey, M.N. Rosenbluth, J. Schivell, G.L. Schmidt, S.D. Scott, G. Taylor, and R.M. Wieland, "Advances in Transport Understanding Using Perturbative Techniques in TFTR," "i Plasma Physics and Controlled Nuclear Fusion Research 1990 (IAEA, Vienna, 1991), vol. 1, p. 109.

Y.Z. Zhang and S.M. Mahajan, "Impurity and neutral effects on the dissipative drift wave in tokamak edge plasmas," Phys. Fluids B 4, 207 (1992).

Y.Z. Zhang and S.M. Mahajan, "Edge turbulence scaling with shear flow," Phys. Fluids B 4, 1385 (1992).

Y. Z. Zhang, " $m=1$ Kink Mode for Layer Width Comparable to the Ion Larmor Radius," Phys. Fluids B 3, 351 (1991).

Y. Z. Zhang and S.M. Mahajan, "On Broken Ballooning Symmetry", Phys. Lett. A 157, 133 (1991). 
IFS VISITORS $-\mathbf{1 9 9 1 - 9 2}$

Name

BIALYNICKI-BIRULA,

Iwo

BREIZMAN, Boris

CARY, John

CHE'JNG, L.

CHOI, Duk-In

COWLEY, Steve

COWLEY, Steve

CRAWFORD, John D.

CRAWFORD, John David

DENTON, Richard

DEWAR, Robert

DIMITS, Andris

DRAKE, Jim

ERNST, Darin

EROKHIN, N.S.

ESIPCHUK, Yu. V.

HAMANATSU, Kiyotaka
Institution

Polish Academy of Sciences

Inst Nucl Phys., Novosibirsk, RUSSIA

Univ. of Colorado, Boulder

Tunghei Univ., Taiwan

KAIST, Korea

Princeton Plasma Phys. Lab

Princeton Plasma Physics Lab

University of Pittsburgh

University of Pittsburgh

Dartmouth College

Australian National University

Lawrence Livernore Natl Lab

University of Maryland

MIT

Space Research Institute, Moscow

Kurchatov Institute, Moscow

J.A.E.R.I., Japan
Dates of Viejt

Sept. 11-21, 1991

January 8, 1992-January 1, 1993

Feb. 6-7, 1992

Sept. 1, 1991-August 31, 1992

July $17-19,1991$

October 13-15, 1991

February 25-28, 1992

January 5-10, 1992

April 30-May 16, 1992

March 25-27, 1992

Nov. 9,1991-Jan. 24, 1992

March 4-6, 1992

February 24, 1992

June 24-August 31, 1991

July $15-24,1991$

Sept. 22-Nov. 3, 1991

March 11-13, 1992 


\section{IFS VISITORS $-1991-92$}

\begin{tabular}{|c|c|c|}
\hline Name & Institution & Dates of Vigit \\
\hline HOJO, $\mathrm{H}$. & Univ. of Tsukuba, Japan & March 19-April 26, 1992 \\
\hline HUA, Daniel & Univ. of California, Berkeley & October 12-14, 1991 \\
\hline ICHIGUCHI, Katsuji & $\begin{array}{l}\text { Natl. Institute for Fusion Science, } \\
\text { Nagoya, Japan }\end{array}$ & April $1-4,1992$ \\
\hline ICHIKAWA, Yoshi & $\begin{array}{l}\text { Natl. Inst. for Fusion Science, } \\
\text { Nagoya, Japan }\end{array}$ & August $11-17,1991$ \\
\hline IIYOSHI, Atsuo & $\begin{array}{l}\text { Natl. Inst. for Fusion Science, } \\
\text { Nagoya, Japan }\end{array}$ & October 29-30, 1991 \\
\hline ISHIGURO, S. & Tokoku Univ., Sendai Japan & Sept. 19-Oct. 3, 1991 \\
\hline ITO, Masataka & Tokyo Gakugei Univ., Japan & Aug. 15, 1991-Jan. 9, 1992 \\
\hline JACKSON, G.L. & General Atomics, San Diego & December 9, 1991 \\
\hline JOVANOVIC, Dusan & Inst of Physics, Czechoslovakia & April 8-June 10, 1992 \\
\hline KIESLING, Michael & Dartmouth College & March 2-3, 1992 \\
\hline KIM, Yil Bong & UCSD, Dept of Physics & November 25, 1991 \\
\hline KISHIMOTO, Yasuaki & J.A.E.R.I.-Japan & Nov. 10,'91-Nov.8,'92 \\
\hline KO'TELNIKOV, Igor & $\begin{array}{l}\text { Inst. of Nucl. Phys., Novosibirsk, } \\
\text { Russia }\end{array}$ & Sept. 29-Dec. 25, 1991 \\
\hline LIU, Jixing & Academia Sinica, Beijing, China & May 1-August 1, 1992 \\
\hline MASCHKE, Eric & Cadarache, France & April 11-30, 1992 \\
\hline MATSUMOTO, Ryoji & Chiba University, Japan & Aug. 5-Sept. 27, 1991 \\
\hline MATSUMOTO, Ryoji & Chiba University, Japan & March 11-April 8, 1992 \\
\hline
\end{tabular}




\section{IFS VISITORS -1991-92}

\section{Name}

MEERSON, Baruch

MINESHIGE, $S$.

MOISEEV, $\mathbf{S}$.

NAKAMURA, Y'uji

OHNISHI, Masami

PASTUKHOV, Vladimir

PETVIASHVILI, Nickolay

PETVIASHVILI, Vladimir

PHIRSCH, Dieter

PORCELLI, Franco

ROSTOKER, Norman

SCOTT, Steven

SEDLACEK, Zdenek

SHAING, Ker-Chung

SHAING, Ker-Chung

SMITH, Ralph

TAKAMARU, $\mathrm{H}$.

\section{Institution}

Hebrew Univ. of Jerusalem, Israel

Univ. of Tokyo, Iapan

Space Research Institute, Moscow

Kyoto University, Japan

Kyoto University, Japan

Kurchatov Institute, Moscow, Russia

Schmidt Inst. of Phys of the Earth, Moscow

Kurchatov Inst., Moscow, Russia

Max-Planck IPP, Germany

JET , Culham, England

Univ, of California, Irvine

Princeton Plasma Physics Lab

IPP Czechuslovak Academy of Sciences

Oak Ridge National Lab

Oak Ridge National Lab

UCSD, La Jolla

N.I.F.S., Nagoya, Japan
Dates of Visit

January 7-February 12, 1992

July 19-29, 1991

July 15-24, 1991

Nov. 9-December 4, 1991

July 25-Sept. 1, 1991

Jan. 24-April 22, 1992

June 28-Aug. 31, 1991

August 11-17, 1991

March 1-31, 1992

March 8-April 5, 1992

April 1-June 30, 1992

February 10, 1992

March 15-June 15, 1992

October 19-25, 1991

March 29-30, 1992

March 10-12, 1992

April 14, 1992 


\section{IFS VISITORS -1991-92}

Name

TANAKA, Motohiko

TANI, Keiji

TANIUITI, TOSIYA

TASSO, Henri

TAYLOR, Bryan

TAYLOR, Bryan

THYAGARAJA, A.

TSIDULKO, Yuri

WAELBROECK, F.L.

WARE, Andrew

WONG, King Lap

XU, Xue

YUSHMANOV, P.N.

YUSHMANOV, P.N.

ZAKHAROV, Leonid

ZONCA, Fulvio
Institution

N.I.F.S., Nagoya, Japan

J.A.E.R.I., Japan

Nagoya, Japan

Max-Planck Institut fur

Plasmaphysik, Germany

United Kingdom

United Kingdom

Culham Laboratory, United Kingdom

INP, Novosibirsk, Russia

Univ. of Maryland

Univ. of California, San Diego

Princeton Plasma Phys. Lab.

Univ. of California, Berkeley

Kurchatov Institute, Moscow, Russia

Kurchatov Institute, Moscow, Russia

Kurchatov Institute, Moscow, Russia

ENEA, Frascati
Dates of Vis!:

January 13-24, 1992

March 11-13, 1992

Feb. 9-April 1, 1992

January 12-31, 1992

Nov. 8-14, 1991

April 9-23, 1992

March 16-18, 1992

May 6-July 20, 1992

Sept. 17-Oct. 2, 1991

April 23-24, 1992

October 19-21, 1991

April 2-3, 1992

Sept. 22-Nov. 3, 1991

January 12, 1992 (for 2 years)

April 9-10, 1992

April 9-10, 1992 
\#500

IMPURITY AND NEUTRAL EFFECTS ON THE DISSIPATIVE DRIFT WAVE IN TOKAMAK EDGE PLASMAS

by Y.Z. ZHANG AND S.M. MAHAJAN

PHYS. FLUIDS B4, 207 (1992)

\# 501

ION TEMPERATURE GRADIENT DRIVEN TRANSPORT IN A DENSITY

MODIFICATION EXPERIMENT ON THE TFTR TOKAMAK

by W. HORTON, ET AL.

PHYS. FLUIDS B4, 953 (1992)

\#502

EXCITATION OF NONLINEAR WAKEFIELD IN A PLASMA FOR PARTICLE ACCELERATION

by B. BREIZMAN, D.L. FISHER, P.Z. CHEBOTAEV, \& T. TAJIMA

Publ. in "Research Trends in Nonlinear \& Relativistic Effects in Plasmas", ed. V. Stefan (AIP, New York, 1991)

\# 503

POWER LAW ENERGY SPECTRUM AND ORBITAL STOCHASTICITY

by K. MIMA, W. HORTON, T. TAJIMA AND A. HASEGAWA

6/91, in Nonlinear Dynamics \& Particle Acceleration, eds. Y.H. Ichikawa and T. Tajima, AIP, New York, p. 27, 1991

\#04

A MESOSCOPIC LINEAR ACCELERATOR DRIVEN BY SUPERINTENSE

SUBPICOSECOND LASER PULSES

by B. MEERSON AND T. TAJIMA.

OPT. COMM. 86, 283 (1991)

$\# 505$

SHOCK FORMATION IN A POLOIDALLY ROTATING TOKAMAK PLASMA

by K.C. SHAING, R.D. HAZELTINE AND H. SANUKI

PHYS. FLUIDS B4, 404 (1992)

\#506

MAGNETOHYDRODYNAMIC STUDIES OF IDEAL AND RESISTIVE TEARING MODES WITH EQUILIBRIUM SHEAR FLOW

by XIAO-LIANG CHEN

DISSERTATION (6/91)

\# 507

FINITE ORBIT ENERGETIC PARTICLE LINEAR RESPONSE TO TOROIDAL ALFVEN EIGENMODES

by H.L. BERK, B. BREIZMAN AND H. YE

PHYS. LETTS. A162, 475 (1992) 
IFS REPORTS (1991-1992)

\#508

KINETIC THEORY OF RF CURRENT DRIVE AND HELICITY INJECTION

by R. METT

PHYS. FLUIDS B4, 225 (1992)

\# 509

GEOMETRIC PHASE, ROTATIONAL TRANSFORMS AND ADIABATIC

INVARIANTS IN TOROIDAL MAGNETIC FIELDS

by A. BHATTACHARJEE, G.M. SCHREIBER, AND J.B. TAYLOR

SUBMITTED TO PHYSICAL REVIEW A (JULY, 1991)

\#510

ASYMPTOTIC SPECTRA IN TWO-DIMENSIONAL DRIFT WAVE TURBULENCE by Y.Z. ZHANG

SUBMITTED TO PHYS. REVIEW LETTERS (JULY, 1991)

\#511

NONLINEAR INTERACTIONS OF TEARING MODES IN THE PRESENCE OF SHEAR FLOW

by X.L. CHEN AND P.J. MORRISON

PHYS FLUIDS B4, 845 (1992)

\#512

VLASOV-MAXWELL SYSTEM: 2-D EQUILIBRIA, REVERSED FIELD PINCHES by S.M. MAHAJAN, W.Q. LI AND A. SEN

Submitted for publication in PHYS. FLUTDS (8/91)

\#513

QUANTUM-MECHANICS AS A GENERALIZATION OF NAMBU DYNAMICS TO THE WEYL-WIGNER FORMALISM

by IWO BIALYNICKI-BIRULA AND P.J. MORRISON

PHYS. LETTS. A158, 453 (1991)

\#514

FORM INVARIANCE IN CONVECTIVE-DIFFUSIVE SYSTEMS WITH

APPLICATIONS TO IMPURITY TRANSPORT

by S.M. MAHAJAN, P.M. VALANJU, AND WILLIAM L. ROWAN

To be published in PHYS. FLUIDS (8/92)

\#515

EFFECTS OF A STRATIFIED ATMOSPHERE ON THE PRODUCTION OF X-RAY AND PARTICLE ENERGY SPECTRA IN SOLAR FLARES

by KATHERINE HOLCOMB, TOSHIKI TAJIMA AND BARUCH MEERSON

Astrophys. Journal 378, 682 (1991) 


\section{IFS REPORTS (1991-1992)}

\# 516 STABILIZATION OF THE M=1 TEARING MODE BY RESONANCE DETUNING by A. THYAGARAJA, R.D. HAZELTINE, AND A.Y. AYDEMIR

Submitted for publication in PHYS. FLUIDS B (6/92)

\# 517

ENHANCEMENT OF CURRENT DIFFUSION IN IE PRESENCE OF A KINK MODE OR AN ALFVEN WAVE

by A.D. BEKLEMISHEV

Submitted for publication in PHYS. FLUIDS (8/91)

\#518

CONTINUUM DAMPING OF HIGH-MODE-NUMBER TOROIDAL ALFVEN WA VES

by M.N. ROSENBLUTH, H.L. BERK, D. LINDBERG AND J.W. VAN DAM

PHYS. REV. LETTS. 68, 596 (1992)

\# 519

PRELIMINARY ABSTRACTS - US-JAPAN WORKSHOP ON NUCLEAR FUSION IN DENSE PLASMAS

by T. TAJIMA AND S. ICHIMARU

\#520

NEO-BALLOONING THEORY VIA SPONTANEOUS SYMMETRY BREAKING by Y.Z.ZHANG

Submitted for publication in PHYS. LETTS. A (9/91)

$\# 521$

MONOPOLE VORTICES IN INHOMOGENEOUS PLASMAS

by W. HORTON, X. SU AND P.J. MORRISON

Proceedings of the III Potsdam.V Kiev Intl. Workshop on Nonlinear Processes in Physics, eds. A. Fokas, D. Kaup, and Zakharov, to appear.

\# 522 PARTICle Simulation OF NON-CIRCUlar TOROIDAl PlaSMas IN NON-ORTHOGONAL CURVILINEAR COORDINATES

by K. UMF.GAKI, M.J. LEBRUN, AND T. TAJIMA

\#523

DRIFT WAVE VORTICES IN NONUNIFORM PLASMAS AND SHEARED MAGNETIC FIELDS

by X.N. SU, W. HORTON, AND P.J. MORRISON

PHYS. FLUIDS B 4, 1238 (1992) 


\section{IFS REPORTS (1991-1992)}

$\# 524$

NEOCLASSICAL DIFFUSION IN A TURBULENT PLASMA

by P. YUSHMANOV

COMMENTS PLASMA PHYS. \& CONT. FUSION 14, 313 (1992)

\# 525

SELF.CONSISTENT RADIAL SHEATH IN IGNITED PLASMAS

by H. XIAO, R. CARRERA, AND R.D. HAZELTINE

NUCL. FUS. 31, 2162 (1991)

\# 526

EDGE TURBULENCE SCALING WITHI SHEAR FLOW

by Y.Z. ZHANG AND S.M. MAHAJAN

PHYS FLUIDS B4, 1385 (1992)

\#527

TOROIDAL KINETIC ETA-I MODE STUDY IN HIGH TEMPERATURE PLASMAS

by J.Q. DONG, W.C. HORTON, AND J. Y. KIM

PHYS FLUIDS B4, 1867 (1992)

\section{\# 528 R \\ PERCOLATION, STATISTICAL TOPOGRAPHY, AND TRANSPORT IN RANDOM MEDIA}

by M.B. ISICHENKO

To appear in REV. MOD. PHYS. 64(4), (1992)

\# 529

ANOMALOUS ION THERMAL DIFFUSION FROM ETA-I MODES

by A. BEKLEMISHEV AND W. HORTON

PHYS FLUIDS B4, 2176 (1992)

\#530

NONLINEAR EVOLUTION OF RESISTIVE TEARING MODE WITH SHEAR

FLOW VISCOSITY

by L. OFMAN, X.L. CHEN, P.J. MORRISON, AND R. STEINOLFSON

Submitted to PHYS FLUIDS B (3/92)

\#531

EXISTENCE AND DAMPING OF TOROIDICITY-INDUCED ALFVEN

EIGENMODES

by S.M. MAHAJAN AND R.R. METT

To be published in PHYS. FLUIDS (9/92) 
\#532

COMPARISONS OF THEORETICALLY PREDICTED TRANSPORT FROM ION TEMPERATURE GRADIENT INSTABILITIES TO L-MODE TOKAMAK EXPERIMENTS

by M. KOTSCHENREUTHER, V. WONG, P. LYSTER, H.L. BERK, R. DENTON, W.M. MINER, AND P. VALANIU

SUBMITTED TO PHYS REV LETTERS (12/91)

\#533

ON ZERO FREQUENCY MAGNE IC FLUCTUATIONS IN PLASMAS

by T. TAJIMA, S. CABLE, AND R.M. KULSRUD

PHYS FLUIDS B4, 2338 (1992)

\#534

SELF-CONSISTANT THEORY FOR ION GYRORESONANCE

by H. YE AND A.N. KAUFMAN

PHYS. FLUIDS B4, 1735 (1992)

\# 535

MAGNETIC SURFACES IN A STEADY-STATE. TOKAMAK

by R. KINNEY, T. TAJIMA, AND H. IRIE

SUBMITTED TO PHYS FLUIDS B (4/92)

\#536

EXCITATION OF SOLITONS BY AN EXTERNAL RESONANT WAVE WITH A SLOWLY VARYING PHASE VELOCITY

by IGOR ARANSON, BARUCH MEERSON, AND TOSHI TAJIMA

PHYS. REV. A45, 7500 (1992)

\#537

MODE STRUCTURE AND CONTINUUM DAMPING OF HIGN-N TOROIDAL ALFVEN EIGENMODES

by M.N. ROSENBLUTH, H.L. BERK, J.W. VAN DAM, AND D.M. LINDBERG

PHYS. FLUIDS B4, 2189 (1992)

\#538

THE PlPLOT PLOTTING LIBRARY PROGRAMMER'S REFERENCE MANUAL VERSION 4.0

by M. LEBRUN, G. FURNISH, AND TONY RICHARDSON

\#539

EFFECTS OF ORBIT SQUEEZING ON ION TRANSPORT IN THE BANANA REGIME IN TOKAMAKS

by K.C. SHAING AND R.D. HAZELTINE

Accepted for publication in PHYS FLUIDS (5/92) 
IFS REPORTS (1991-1992)

$\# 540$

THE EFFECT OF CHARGE-EXCHANGE ON PLASMA FLOWS

by P.M. VAL.ANIU, M. CALVIN, R.D. HAZELTINE, AND E. SOLAND

Accepted for publication in PHYS. FhuUIDS B (5/92)

$\# 541$

LOW FREQUENCY FLUCTUATIONS IN PLASMA MAGNETIC FIELDS

by S. CABLEAND T. TAJIMA

SUBMITTED TO PHY REV A (2/92)

\# 542

SCENARIOS FOR THE NONLINEAR EVOLUTION OF ALPHA PARTICLE

INDUCED ALFVEN WAVE INSTABILITY

by H.L. BERK. B.N. BREIZMAN, AND HUANCHUN YE

SUBMITTED TO PHYS REV LETTERS (3/92)

\#43

KINETIC THEORY OF TOROIDICITY-INDUCED ALFVEN EIGENMODES

by RICHARD METT AND SWADESH MAHAJAN

To be published in PHYS. FI.LIIDS (9/92)

\section{\# 544}

THE RAYLEIGH.TAYLOR INSTABILITY IN AN EXPANDING PLASMA

by S. CABLEE AND TOSHI TAIIMA

SUBMITTED TO PHYS. REY. B (3/92)

\section{\#5.45}

DIELECTRIC ENE IGY VS. PLASMA ENERGY AND HAMILTONIAN

ACTION-ANGLE " ARIABIES FOR THE VLASOV EQUATION

by P.J. MOR ¿ISON AND DIETER PFIRSCH

To appear in PHYS. FLULDS (October, 1992)

\#546

NEUTRAL MODES AND NEGATIVE ENERGY WAVES

by B. SH.ADWICK AND P.J.MORRISON

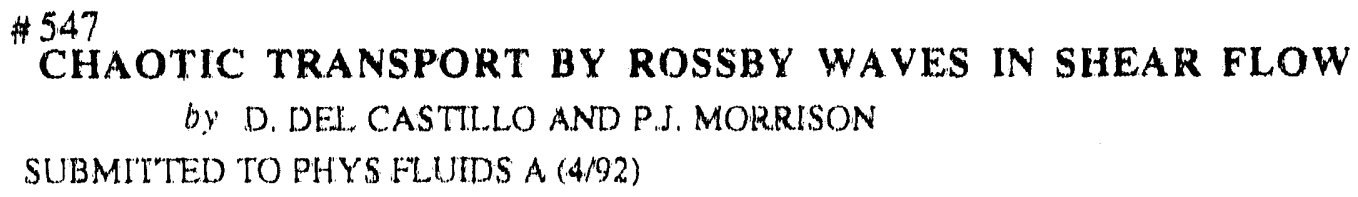

\#547

CHAOTIC TRANSPORT BY RDSSBY WAVES IN SHEAR FLOW

by D. DEI. CASTTLLLO AND P.J. MORRISON

SUBMITTED TO PHYS FLUTDS A (4/92)

\section{\#548}

QUASI-THREE DIMENSIONAL ELECTRON HOLES IN MAGNETIZED PLASMAS by D. JOVANOVIC AND W. HORTON 
IFS REPORTS (1991-1992)

\# 549

VORTICES ASSOCIATED WITH TOROIDAL ION TEMPERATURE GRADIENT DRIVEN FLUCTUATIONS

by W. HORTON, D. JOVANOVIC AND J. RASMUSSEN

Submitted for publication in PHYS. FLUIDS B (5/92)

\#550

TWO DIMENSIONAL ASPECTS OF TOROIDAL DRIF WAVES IN THE

BALLOONING REPRESENTATION

by Y.Z. ZHANG, S.M. MAHAJAN, AND X.D. ZHANG

Accepted for publication in PHYS FLUTDS B (5/92)

\#551

STOCHASTIC DIFFUSION AND KOLMOGOROV ENTROPY IN REGULAR AND RANDOM HAMILTONIANS

by M. ISICHENKO, W. HOR'TON, J-Y, KIM, HEN AND CHOI

SUBMITTED FOR PUBLICATION IN PHYS FLUIDS B (5/92)

\#552

RESISTIVE MHD STUDIES OF TEARING MODE INSTABILITY WITH

EQUILIBRIUM SHEAR FLOW AND MAGNETIC RECONNECTION

by LEON OFMAN

THESIS

\#55

DELETED

by

\#554

AMPIIFICATION MECHANISM OF ION RIPPLE LASERS AND ITS POSSIBLE APPLICATION

ION NIPPLE LASER

and

by K.R. CHEN AND JOHN DAWSON

SUBMITTED TO IEEE TRANS. ON PLASMA SCIENCE (4/92); PHYS. REV. LETTS. 68, 29 (1992)

\#555

EXPLICIT, ANALYTICAL AND NUMERICAL, SOLUTION OF THE NONLINEAR VLASOV POISSON SYSTEM

by S.M. MAHAJAN, V. SKARKA, AND E. FUALKOW

SUBMITTED TO PHYS FLUIDS B (6/92)

\#556

FAST ION-DRIVEN BERNSTEIN INSTABILITIES

by K.R. CHEN

SUBMITTED TO PHYS. REV. LETTS. (6/92) 
\#557

THEORIES OF FAST-ION-DRIVEN BERNSTEIN INSTABILITIES

by K.R. CHEN

TOBES _ MITTED TO PHYS FLUIDS B

\#558

MAGNETIC FUSION WITH HIGH ENERGY SELF.COLLIDING ION BEAMS

by N. ROSTOKER, F. WESSEL, B. MAGLICH AND A. FISHER

CONTRIBUTED PAPER TO BEAMS'92 CONFERENCE

\#559

FAST MAGNETIC FIELd PENETRATION INTO AN INTENSE NEUTRALIZED ION BEAM

by R. ARMALE AND N. ROSTOKER

CORTRIBUTED PAPER TO BEAMS'92 CONFERENCE

\#560

NONLINEAR STUDIES OF M=1 MODES IN SEMI-COLLISIONAL AND

COLLISIONLESS REGIMES

by A.Y. AYDEMIR

SUBMITTED TO PHYS FLUIDS (7/92)

\#561

THE ELECTROSTATIC WAKE OF A SUPERTHERMAL TEST ELECTRON IN A MAGNETIZED PLASMA

by A.A. WARE ANDD J.C. WILEY 

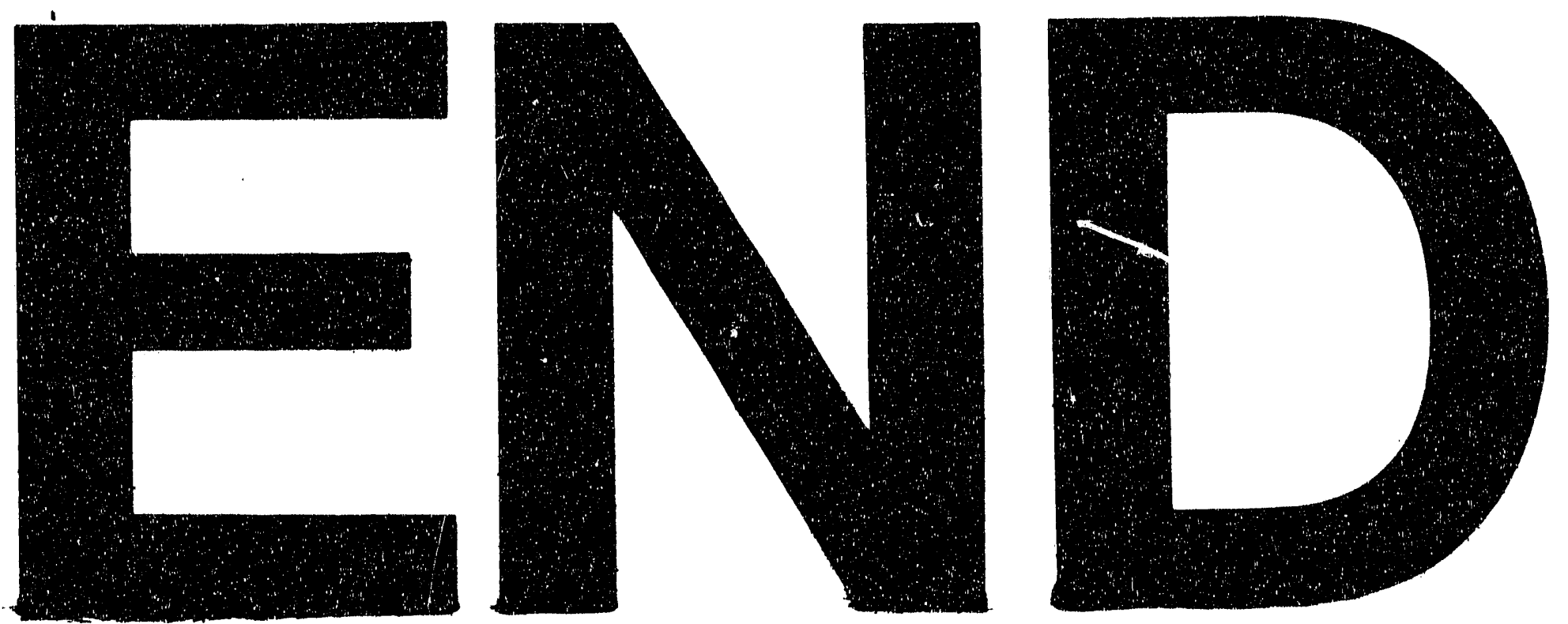

..
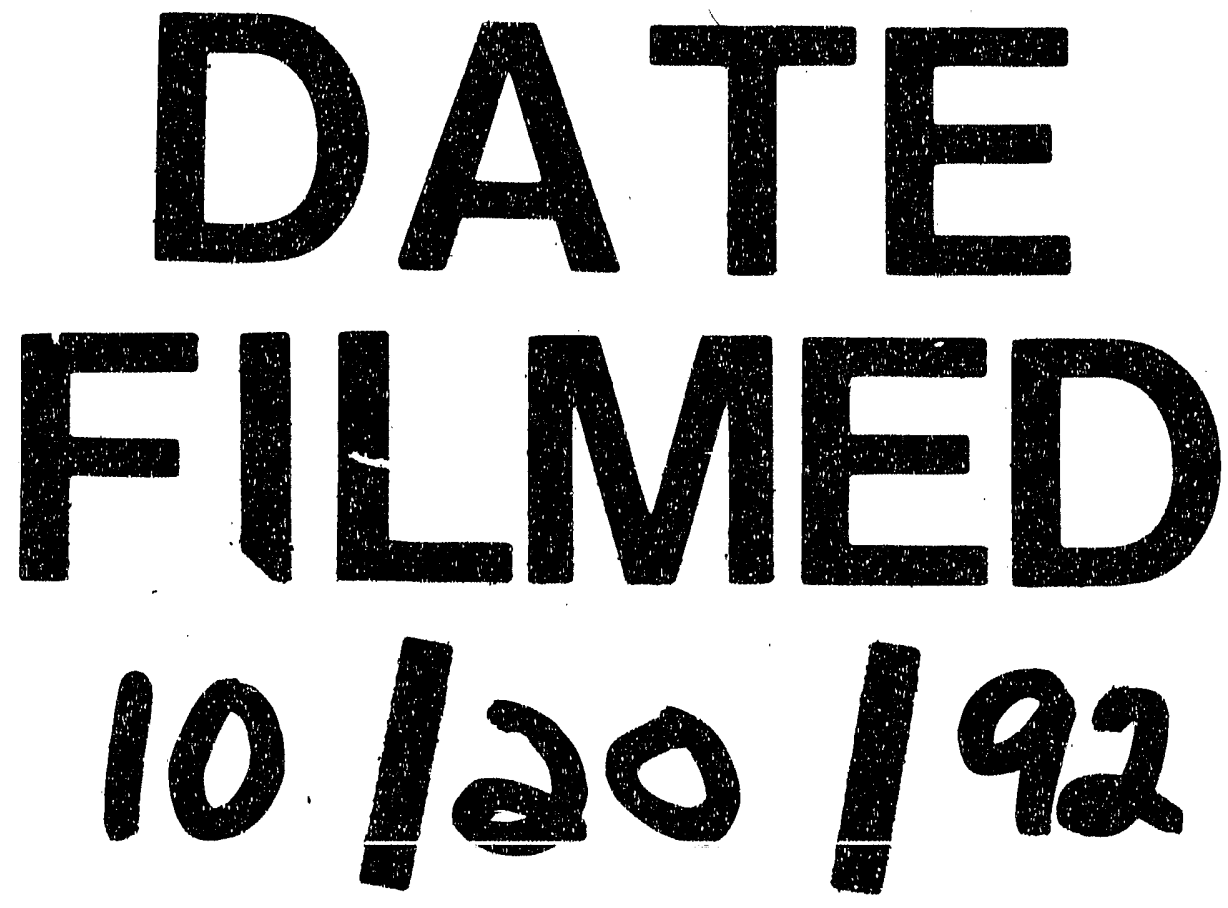
